\title{
Hemiablation of Localized Prostate Cancer by High-Intensity Focused Ultrasound: A Series of 35 Cases
}

\author{
Peter V. Glybochko Alexander V. Amosov German E. Krupinov \\ Nikolay V. Petrovskii Ilya S. Lumpov
}

Institute for Urology and Reproductive Health, First Moscow State Medical University (Sechenov University), Moscow, Russia

\section{Keywords}

Prostate cancer · Focal therapy · HIFU ablation · Ultrasound hemiablation

\begin{abstract}
Prostate cancer $(\operatorname{PrC})$ is one of the most common tumors diagnosed in men. The detection rate of localized PrC has been dramatically enhanced by screening and the development of visualization methods. There are currently several techniques for focal treatment available, among which the most interesting in our opinion is high-intensity focused ultrasound (HIFU). Currently, HIFU hemiablation of $\operatorname{PrC}$ is not an established treatment, although evidence of its effectiveness and safety is growing. We have been performing HIFU hemiablation since 2013 and here report our results to add to the evidence on the effectiveness of the technique. Between October 2013 and December 2016, we performed HIFU hemiablation of the prostate for a total of 35 patients with confirmed $\operatorname{PrC}$ stage $<$ CT2a at our urology clinic and retrospectively examined duration of ablation, pre- and postoperative prostate-specific antigen (PSA) levels, prostate volume, erectile function, and dysuria. The mean duration of ablation was $22 \mathrm{~min}$ (10-35). The mean postoperative hospital stay was 4 days. None of the patients experienced serious complications. Postoperative PSA tests showed the greatest
\end{abstract}

\section{KARGER}

E-Mail karger@karger.com www.karger.com/ocl
(C) 2019 The Author(s)

Published by S. Karger AG, Basel

Karge

Open access

This article is licensed under the Creative Commons AttributionNC-ND) (http://www.karger.com/Services/OpenAccessLicense). Usage and distribution for commercial purposes as well as any disNonCommercial-NoDerivatives 4.0 International License (CC BY tribution of modified material requires written permission. decrease after 3 months to $2.4 \mathrm{ng} / \mathrm{mL}$ on average $(p<0.001)$. The pathological focus seen on MRI before the procedure in each case was absent after 3 months. Control biopsy after 12 months revealed residual cancer in the contralateral lobe in 4 patients. The findings obtained during follow-up and from control biopsies indicate that the treatment was highly efficacious with a low rate of nonserious postoperative complications. HIFU hemiablation proved to be a reliable therapeutic modality for localized $\operatorname{PrC}$ and was associated with a low rate of complications and comparable risk of recurrence. Despite the fact that this method of treatment is currently experimental, the results of this case series and other studies indicate its feasibility and safety. 02019 The Author(s)

Published by S. Karger AG, Basel

\section{Introduction}

Localized forms of low- and intermediate-risk prostate cancer (PrC), which sometimes require no active surgical intervention, are being increasingly detected with the more widespread use of prostate-specific antigen (PSA) in $\mathrm{PrC}$ screening. This increased detectability is mainly attributed to the high sensitivity of PSA combined with the use of ultrasound-guided prostate biopsy [1]. Moreover, the development and implementation in urological 

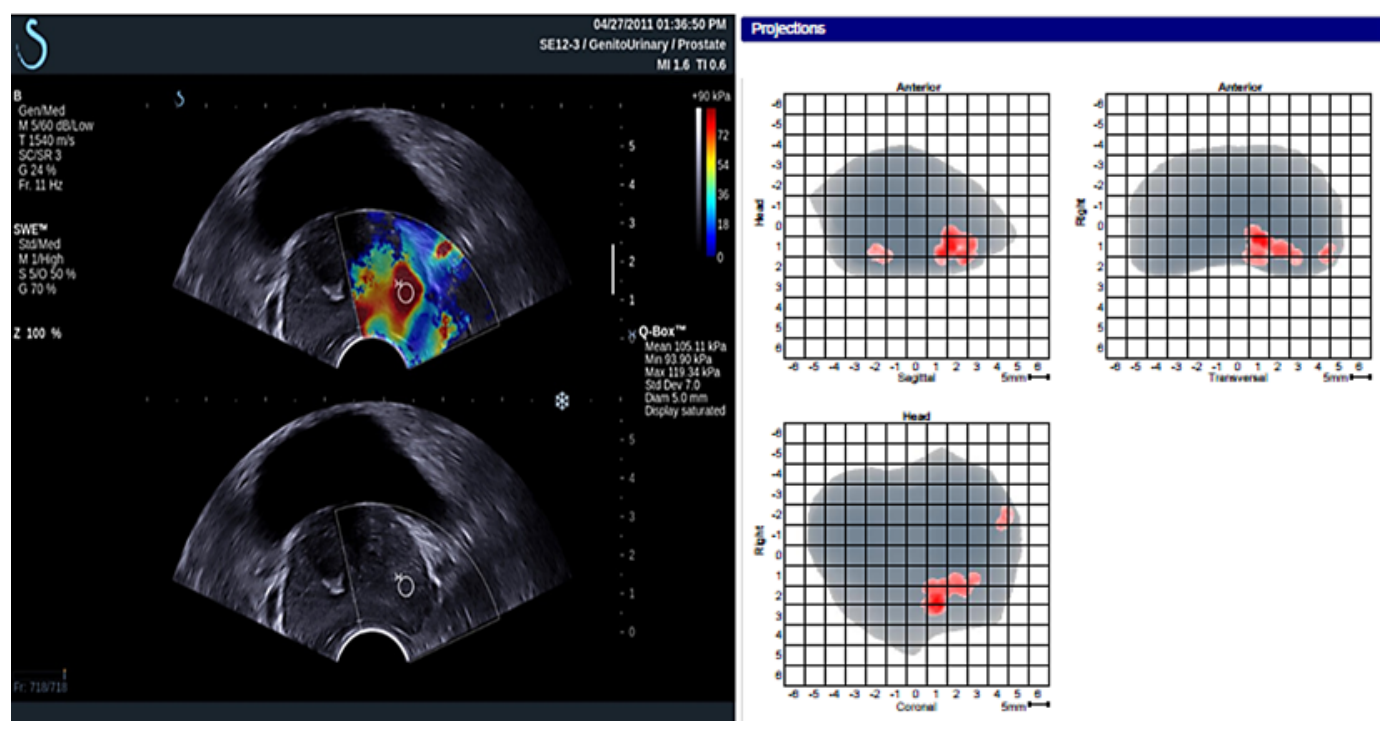

Fig. 1. Preoperative USWE and PHS. Representative preoperative imaging findings for USWE (a) and PHS (b) for monofocal localized prostate cancer.

practice of present-day diagnostic methods such as multiparametric magnetic resonance imaging (MRI), prostate histoscanning (PHS), and ultrasound shear wave elastography (USWE) have allowed for more precise risk stratification. These methods help to identify the specific location of the so-called index lesion, the single tumor focus often present among multiple tumor foci that is considered to be predominately responsible for tumor progression and which is regarded by some as the largest tumor focus present [2]. Hence, focal treatment that is directed precisely at this index lesion and spares healthy prostate tissue is a promising technique to avoid undesirable side effects of treatment.

Currently, however, the gold standard of PrC treatment is radical prostatectomy, which is associated with certain side effects involving the genitourinary tract. Alternatively, a policy of active surveillance aimed at eliminating complications related to radical treatment may be followed, but it carries the risk of psychological stress that can affect quality of life. The middle ground between these two approaches is focal therapy for localized PrC, and early studies on its applicability have demonstrated preservation of genitourinary function and a low complication rate in $90-95 \%$ of patients [3].

Among the different focal treatment modalities available, high-intensity focused ultrasound (HIFU) is as yet an experimental protocol for primary treatment of localized PrC. Focused ultrasound in the real-time mode generates the temperature needed to induce local necrosis in the targeted portion of the gland, and the utility of HIFU for thermal ablation has been confirmed histologically [4-6]. HIFU hemiablation of the prostate as one form of focal treatment has the potential to target only the cancerous tissue within the gland, enabling as much healthy tissue as possible to be spared [7-10]. In this article, we report the effectiveness of HIFU hemiablation of the prostate in a series of 35 consecutive cases of monofocal localized $\operatorname{PrC}$ treated at our urology clinic.

\section{Case Presentations}

Between October 2013 and December 2016, a total of 35 patients (mean age 65 years) with confirmed stage $<$ cT2a monofocal localized PrC (Gleason score $\leq 7$ [11]) revealed in one lobe of the prostate on biopsy underwent HIFU hemiablation at our urology clinic at the First Moscow State Medical University. The mean PSA level prior to treatment was $7.8 \mathrm{ng} / \mathrm{mL}$, and the volume of the prostate ranged from 23 to $90 \mathrm{~cm}^{3}$. The maximum urine flow rate was $17 \mathrm{~mL} / \mathrm{s}$.

As preoperative preparation to determine the location and amount of damaged tissue, patients underwent contrast-enhanced MRI, PHS, and USWE, followed by transrectal puncture biopsy of the prostate guided by the computer-assisted ultrasonographic system Prostate HistoScanning ${ }^{\mathrm{TM}}$ (Advanced Medical Diagnostics, Waterloo, Belgium), which makes it possible to precisely obtain fragments of tissue from suspicious portions of the lesion. Figure 1 shows USWE and PHS images from representative cases. For 
Fig. 2. Preoperative USWE and PHS. Representative MRI control findings of the pathological focus (arrows) before HIFU hemiablation (a) and its disappearance 3 months after the procedure (b).
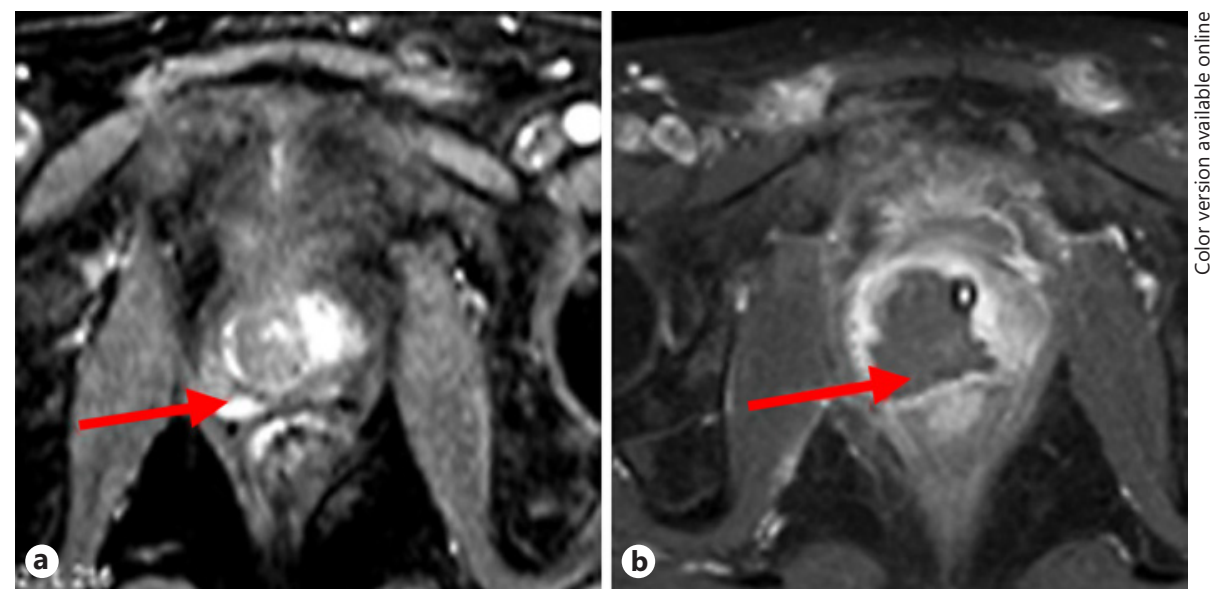

Fig. 3. Dynamics of PSA before and after hemiablation. Box plot showing changes in PSA level before and after HIFU hemiablation $(n=35)$. The line indicates the mean, the box indicates the interquartile range, and whiskers indicate the maximum and minimum values.

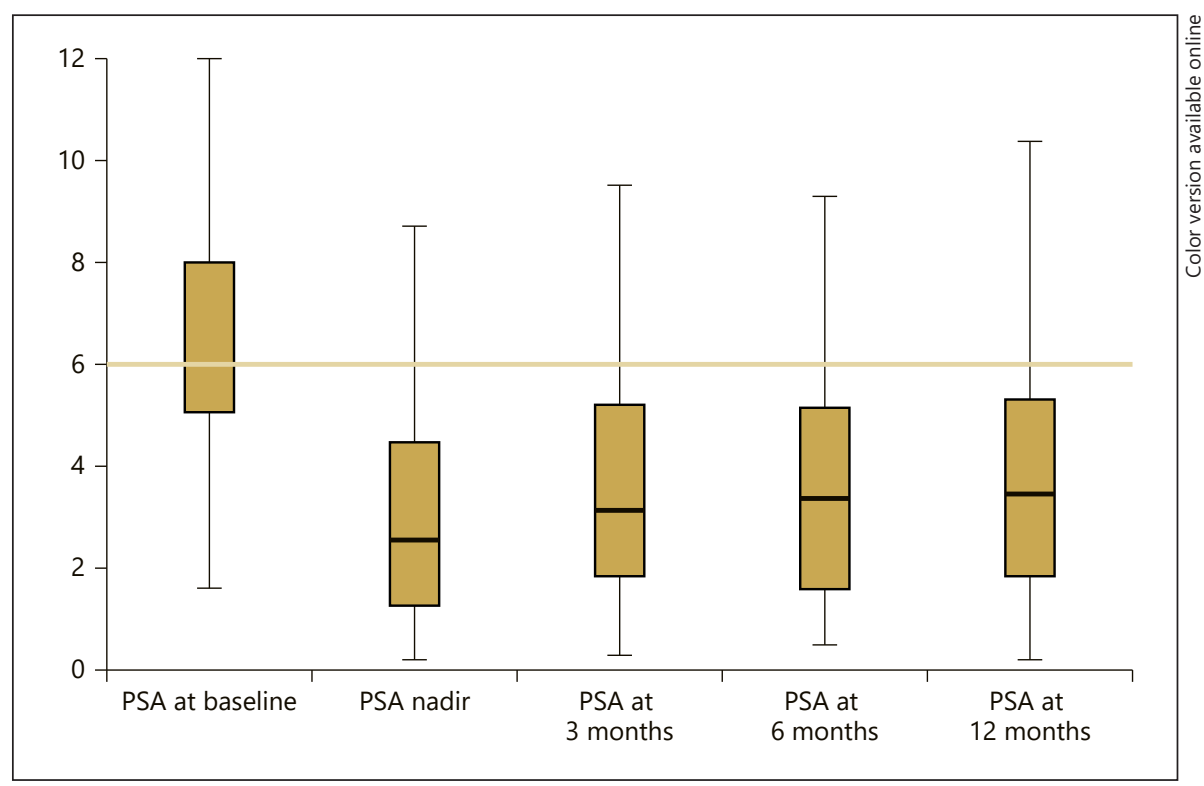

comparison, 3 patients were evaluated using MRI, USWE, and PHS but underwent transperineal template biopsy of the prostate rather than transrectal biopsy, with the results for the primary tumor location corresponding to the findings of MRI, USWE, and PHS. Although HIFU hemiablation may be carried out without prior transurethral resection (TUR) of the prostate, 15 of our 35 patients $(42 \%)$ with a prostate volume of $40-90 \mathrm{~cm}^{3}$ required TUR as first-stage treatment in order to eliminate irritative symptoms. Treatment was performed using the Ablatherm HIFU device (EDAP-TMS, Lyon, France) under spinal anesthesia. Treatment for one lobe extended from the lateral contour to the transitory zone at a distance of $5 \mathrm{~mm}$ from the apex to the basal portions. Prior to focal HIFU ablation, all patients underwent urinary bladder catheterization with a urethral catheter.

Retrospectively, we examined the following parameters: duration of ablation, pre- and postoperative PSA levels, prostate volume, erectile function, and dysuria. The mean duration of ablation was $22 \mathrm{~min}(10-35)$. The mean postoperative hospital stay was 4 days. PSA tests performed at 3, 6, and 12 months after hemiablation showed a maximum decrease in the PSA level after 3 months to $2.4 \mathrm{ng} / \mathrm{mL}$ on average $(p<0.001$; IBM SPSS Statistics version 18.0.2). The mean duration of follow-up was 12 months. None of the patients experienced serious complications, except irritative symptoms and an inconsiderable decrease in the urinary flow rate during the first 2 postoperative months. The pathological focus seen on MRI of the prostate before the procedure in each case was absent 3 months after the procedure (Fig. 2). At 6 months after hemiablation, all patients underwent control biopsy of the prostate and contrast-enhanced MRI, and no pathological foci were evident in the treatment area in any of the patients. Control biopsy performed at 12 months after the operation revealed residual cancer in the contralateral lobe in 4 of our 35 patients. No diagnostically significant increase in PSA was observed during the follow-up period in the remaining 31 patients (Fig. 3).

Erectile function was not significantly decreased at 3 months after HIFU hemiablation according to questionnaire results for the International Prostate Symptom Score (IPSS) and the simplified 
Fig. 4. Dynamics of assessing quality of urination (IPSS) and erectile function (IIEF5) before and 3 months after hemiablation. Box plot showing changes in quality of urination (IPSS score) and erectile function (IIEF-5 score) before and 3 months after hemiablation $(n=35)$. The line indicates the mean, the box indicates the interquartile range, whiskers indicate the maximum and minimum values, and dots show outliers. $p$ values indicate changes from baseline. IPSS, International Prostate Symptom Score; IIEF-5, simplified International Index of Erectile Function.

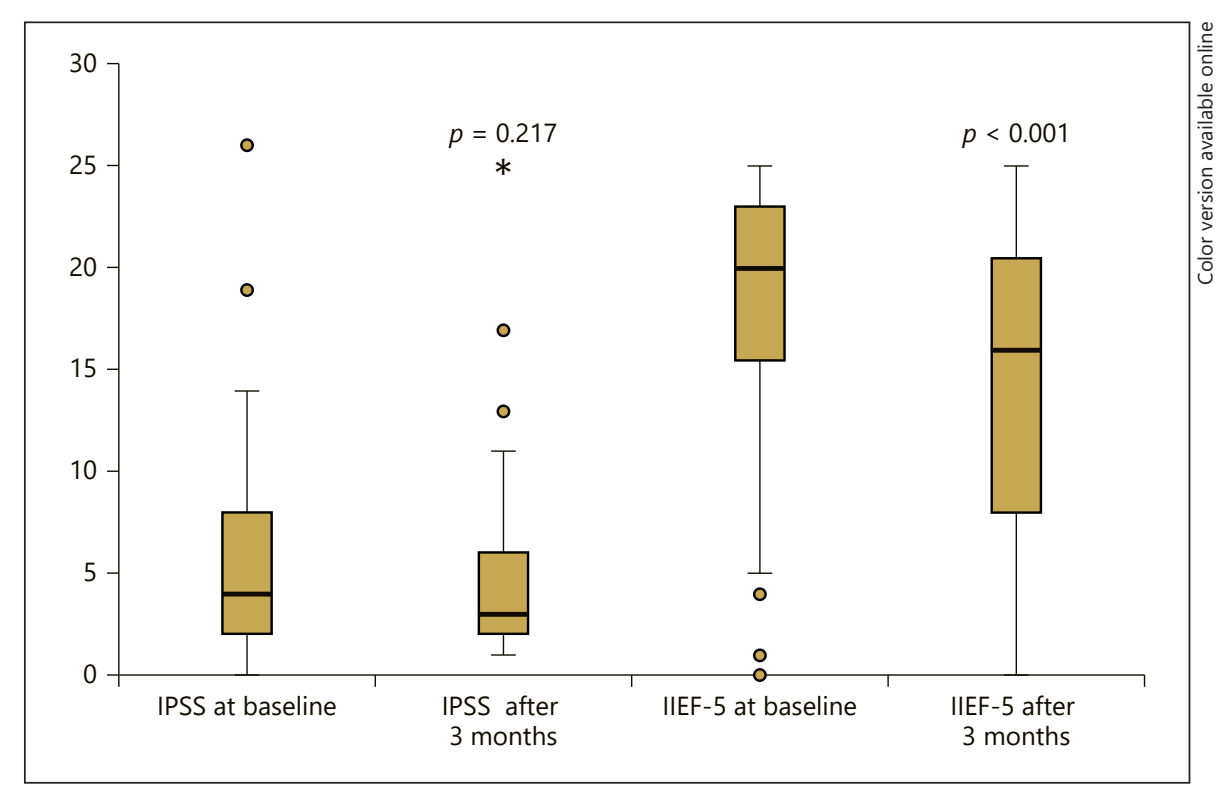

International Index of Erectile Function (IIEF-5) (Fig. 4). However, the 15 patients who underwent TUR of the prostate as firststage treatment were found to have retrograde ejaculation. A further 3 patients were diagnosed as having irritative symptoms.

This study was conducted in accordance with the World Medical Association Declaration of Helsinki and with approval from the institutional review board. Written informed consent was obtained from subjects to publish their cases.

\section{Discussion/Conclusion}

In this case series, overall the minimally invasive procedure of HIFU hemiablation was effective for the treatment of localized PrC. Our results are clinically relevant because the effectiveness and safety of this technique has yet to be established and it is still considered an experimental protocol at present.

One of the first reported uses of HIFU for PrC treatment dates back to 1996. The findings of control biopsy at 1 year revealed no $\mathrm{PrC}$ in 7 of 14 patients who underwent the procedure [12]. Based on some further study of the technique, careful selection of patients is considered vital to perform adequate treatment and achieve satisfactory oncological outcomes. HIFU is generally recommended for patients with localized $\mathrm{PrC}$ of clinical stage $\mathrm{T}_{1}-\mathrm{T}_{2} \mathrm{~N}_{0} \mathrm{M}_{0}$, Gleason score $\leq 7$, PSA baseline level $\leq 15-20$ $\mathrm{ng} / \mathrm{mL}$, and prostate volume $<40 \mathrm{~mL}$ and who are not eligible for radical prostatectomy or who refuse surgical intervention and radiotherapy [11], criteria that we followed in our series.
At present, using HIFU for treatment of the whole gland (both primarily and as salvage therapy) has yielded positive long-term oncological results, with a minimum postoperative complication rate $[13,14]$. Our long-term findings suggest that HIFU is also a suitable option for focal therapy of localized $\operatorname{PrC}$, with the benefits of also minimizing postoperative complications, preserving erectile function, and consequently improving quality of life. Taken together, evidence from our case series and other studies indicate that HIFU is a promising technique for the treatment of PrC.

In conclusion, hemiablation of the prostate with HIFU was an effective and minimally invasive focal treatment for PrC in our case series. Focal therapy currently remains an experimental policy of primary treatment for localized PrC, but more and more studies, including ours, are reporting the effectiveness and safety of this technique. However, it should be noted that the success of focal therapy directly depends not only on the type of the energy used but also on the precise localization of PrC. Further implementation in clinical practice also depends on the long-term results of treatment.

\section{Acknowledgement}

The authors thank Caryn Jones (BSC Hons) of ThinkSCIENCE, Tokyo, for editing and medical writing assistance. 


\section{Statement of Ethics}

The authors have no ethical conflicts to disclose.

\section{Disclosure Statement}

The authors have no conflicts of interest to declare.

\section{Funding Sources}

There were no funding sources.

\section{Author Contributions}

All authors have contributed in writing and reviewing the manuscript.

\section{References}

1 Schröder FH, Hugosson J, Roobol MJ, Tammela TL, Ciatto S, Nelen V, et al.; ERSPC Investigators. Screening and prostate-cancer mortality in a randomized European study. N Engl J Med. 2009 Mar;360(13):1320-8.

2 Rosenkrantz AB, Deng FM, Kim S, Lim RP, Hindman N, Mussi TC, et al. Prostate cancer: multiparametric MRI for index lesion localization-a multiple-reader study. AJR Am J Roentgenol. 2012 Oct;199(4):830-7.

3 Ahmed HU, Emberton M. Active surveillance and radical therapy in prostate cancer: can focal therapy offer the middle way? World J Urol. 2008 Oct;26(5):457-67.

4 Chartier-Kastler E, Yonneau L, Conort P, Haertig A, Bitker MO, Richard F. [High intensity focused ultrasound (HIFU) in urology]. Prog Urol. 2000 Dec;10(6):1108-17. French.

5 Chaussy C, Thüroff S. High-intensity focused ultrasound in prostate cancer: results after 3 years. Mol Urol. 2000;4(3):179-82.
6 Alyaev YG, Amosov AV, Krupinov GE, Grigoryan VA, Bezrukov EA, Chalyi ME, et al. [Prostate cancer and HIFU therapy]. Urology. 2007;6:32-8. Russian.

7 Ahmed HU, Pendse D, Illing R, Allen C, van der Meulen JH, Emberton M. Will focal therapy become a standard of care for men with localized prostate cancer? Nat Clin Pract Oncol. 2007 Nov;4(11):632-42.

8 Eggener SE, Scardino PT, Carroll PR, Zelefsky MJ, Sartor O, Hricak H, et al.; International Task Force on Prostate Cancer and the Focal Lesion Paradigm. Focal therapy for localized prostate cancer: a critical appraisal of rationale and modalities. J Urol. 2007 Dec;178(6): 2260-7.

9 Polascik TJ, Mayes JM, Mouraviev V. Nervesparing focal cryoablation of prostate cancer. Curr Opin Urol. 2009 Mar;19(2):182-7.

10 Ahmed HU, Moore C, Lecornet E, Emberton $M$. Focal therapy in prostate cancer: determinants of success and failure. J Endourol. 2010 May;24(5):819-25.
11 Blana A, Walter B, Rogenhofer S, Wieland WF. High-intensity focused ultrasound for the treatment of localized prostate cancer: 5-year experience. Urology. 2004 Feb;63(2): 297-300.

12 Gelet A, Chapelon JY, Bouvier R, Souchon R, Pangaud C, Abdelrahim AF, et al. Treatment of prostate cancer with transrectal focused ultrasound: early clinical experience. Eur Urol. 1996;29(2):174-83.

13 Ahmed HU, Zacharakis E, Dudderidge T, Armitage JN, Scott R, Calleary J, et al. Highintensity-focused ultrasound in the treatment of primary prostate cancer: the first UK series. Br J Cancer. 2009 Jul;101(1):1926.

14 Baco E, Gelet A, Crouzet S, Rud E, Rouvière $\mathrm{O}$, Tonoli-Catez $\mathrm{H}$, et al. Hemi salvage highintensity focused ultrasound (HIFU) in unilateral radiorecurrent prostate cancer: a prospective two-centre study. BJU Int. 2014 Oct; 114(4):532-40. 